\title{
A novel non-trichome based whitefly resistance QTL in Solanum galapagense
}

\author{
Joris Santegoets • Marcella Bovio $\cdot$ Wendy van't Westende $\cdot$ Roeland E. Voorrips • \\ Ben Vosman (1)
}

Received: 2 October 2020/Accepted: 12 January 2021 / Published online: 14 February 2021

(C) The Author(s) 2021

\begin{abstract}
The greenhouse whitefly Trialeurodes vaporariorum is a major threat in tomato cultivation. In greenhouse grown tomatoes non-trichome based whitefly resistance may be better suited than glandular trichome based resistance as glandular trichomes may interfere with biocontrol, which is widely used. Analysis of a collection of recombinant inbred lines derived from a cross between Solanum lycopersicum and Solanum galapagense showed resistance to the whitefly $T$. vaporariorum on plants without glandular trichomes type IV. The resistance affected whitefly adult survival (AS), but not oviposition rate. This indicates that $S$. galapagense, in addition to trichome based resistance, also carries non-trichome based resistance components. The effectiveness of the nontrichome based resistance appeared to depend on the season in which the plants were grown. The resistance also had a small but significant effect on the whitefly Bemisia tabaci, but not on the thrips Frankliniella occidentalis. A segregating $\mathrm{F}_{2}$ population was created to map the non-trichome based resistance. Two Quantitative trait loci (QTLs) for reduced AS of $T$.
\end{abstract}

Supplementary information The online version contains supplementary material available at (https://doi.org/10.1007/ s10681-021-02770-7).

J. Santegoets · M. Bovio - W. van't Westende ·

R. E. Voorrips · B. Vosman ( $\bowtie)$

Plant Breeding, Wageningen University and Research, PO Box 386, 6700 AJ Wageningen, The Netherlands e-mail: ben.vosman@wur.nl vaporariorum were mapped on chromosomes 12 and 7 (explaining $13.9 \%$ and $6.0 \%$ of the variance respectively). The QTL on chromosome 12 was validated in F3 lines.

Keywords Bemisia tabaci $\cdot$ Frankliniella occidentalis - Thrips · Tomato · Trialeurodes vaporariorum

\section{Introduction}

Cultivated tomato, Solanum lycopersicum L., is a crop grown under both open field and greenhouse conditions. It is the leading non-grain commodity in the global production system, with 182 million tons produced in 2018 (FAO 2018). Two whitefly species cause major problems in cultivated tomato: the greenhouse whitefly (Trialeurodes vaporariorum) and the silverleaf whitefly (Bemisia tabaci). They damage the plants by feeding on the phloem, inducing wilting and reducing growth, both in the nymph and adult stages (Johnson et al. 1992). Whiteflies secrete honeydew during feeding, which promotes the growth of sooty mould (Kamikawa et al. 2018; Mansveld et al. 1982). Sooty moulds reduce the photosynthetic capacity of plants by blocking sunlight (Chomnunti et al. 2014). The presence of sooty mould also requires fruits to be washed before marketing. However, the 
main impact of whiteflies on cultivated tomato is due to their role as virus vector, being associated with over 100 pathogenic viruses, including important viruses such as tomato yellow leaf curl virus, tomato infectious chlorosis virus and tomato chlorosis virus (Duffus et al. 1996; Fiallo-Olivé and Navas-Castillo 2019; Jones 2003; Wisler et al. 1998).

Different management strategies are used to control whiteflies in greenhouses, one of which is the use of insecticides. Neonicotinoids (Millar and Denholm 2007), pyrethroids (Soderlund and Bloomquist 1989) and other systemic insecticides (Nauen et al. 2008; Selby et al. 2013) are deployed to minimize the impact of whiteflies on crops. However, due to increased insecticide resistance (Bi and Toscano 2007; Gorman et al. 2007; Horowitz et al. 2007) and growing concerns about the impact of these compounds on human health, environmental effects, and non-target effects (Aktar et al. 2009; Forget 1993; Gerling et al. 2001; Lari et al. 2014), the demand for alternative solutions has increased. Natural enemies of whiteflies are widely used as biocontrol method in greenhouses, including parasitoid wasps such as Encarsia formosa and predatory mites like Amblydromalus limonicus (Knapp et al. 2013; Lahey and Stansly 2015; Vet et al. 1980).

The western flow thrips (Frankliniella occidentalis) is another pest causing problems in tomato cultivation, it feeds on the plants and vectors Tomato spotted wilt virus (Allen and Broadbent 1986). Especially this virus causes a significant reduction in weight, total number, width and length of fruits of infected plants (Sevik and Arli-Sokmen 2012).

An alternative solution for whitefly and thrips management in tomato is the use of host plant resistance (Broekgaarden et al. 2011). As effective levels of resistance are not present in cultivated tomato, wild relatives have been screened for new resistance genes. Whitefly and thrips resistance can be found in tomato wild relatives such as Solanum pennellii, Solanum pimpinellifolium, Solanum galapagense and Solanum habrochaites (De Ponti et al. 1975; Firdaus et al. 2012; McDaniel et al. 2016; Mirnezhad et al. 2010; Muigai et al. 2003; Rakha et al. 2017; Vosman et al. 2018). A major focus in resistance breeding has been the presence of glandular trichomes. Tomato and its wild relatives are known to possess seven types of trichomes, four of which are glandular (Luckwill 1943). Presence of glandular trichomes has been associated with increased whitefly resistance (Erb et al. 1994; Firdaus et al. 2013; Oriani et al. 2011) and thrips resistance (Escobar-Bravo et al. 2018; Mirnezhad et al. 2010). Trichomes can form physical barriers for insects, secrete toxic components or both (Dimock and Kennedy 1983). Glandular trichomes make the handling of tomato plants harder and interfere with biological control agents, as they reduce predation and negatively impact life-history parameters of predatory and parasitoid insects and mites (Riddick and Simmons 2014; Schmidt 2014; Simmons and Gurr 2004). Therefore, in greenhouses where biocontrol is widely used, additional resistance based on non-trichome mechanisms is the only possibility. A well-known non-trichome whitefly resistance gene is the Mi-gene (Roberts and Thomason 1986). While the $M i$-gene is known to confer resistance in tomato to $B$. tabaci, its role in $T$. vaporariorum resistance is not yet proven (Nombela et al. 2003). A non-trichome, non$M i T$. vaporariorum resistance was found in $S$. pimpinellifolium (McDaniel et al. 2016). For thrips, non-trichome based resistance was found in a cultivated tomato line (Bac-Molenaar et al. 2019). In this line, 3 QTL's linked to thrips resistance were identified on chromosomes 4, 5 and 10 and $\alpha$-tomatine was identified as a potential defensive compound.

Solanum galapagense is a close relative of the cultivated tomato that is completely resistant to $T$. vaporariorum (Vosman et al. 2018). This resistance is to a large extent based on glandular trichomes type IV, whose presence is linked to a QTL $(W f-1)$ at the end of chromosome 2 (Firdaus et al. 2013; Vosman et al. 2019, 2018). However, other resistance mechanisms may contribute as well. In this study we focus on nontrichome based resistance towards the greenhouse whitefly $T$. vaporariorum in $S$. galapagense. More specifically we address the questions: (1) is nontrichome based resistance present; (2) does this resistance affect other insect species like $F$. occidentalis; (3) how effective is it and; (4) what is its genetic basis?

\section{Materials and methods}

Plant material and growing conditions

Three recombinant inbred lines (RILs) were selected from the RIL population described by Vosman et al. 
(2019), which are derived from a cross between $S$. lycopersicum (TMV-resistant Moneymaker, PRI91117) and S. galapagense (PRI95004) (Firdaus et al. 2013). These lines (R015, R086 and R169) lack the $W f-1$ allele from $S$. galapagense, but still show an increased resistance towards T. vaporariorum. A few other lines from the same population were used as reference: R020, a RIL line with no increased resistance that also lacks the $W f-1$ allele from $S$. galapagense, and R040, a RIL line with the Wf-1 resistance allele from $S$. galapagense and with a high resistance to $T$. vaporariorum. For the non-trichome based resistance mapping, RIL line R169 was crossed with tomato cultivar Moneymaker (CGN14330) to generate an F1. A single F1 plant was selfed in order to create the F2 population, which was used in the QTL analysis together with cv. Moneymaker and R169 plants. Phenotyping for T. vaporariorum resistance was performed as described below.

For QTL validation, 2 F2 plants heterozygous for the 2-LOD region of the QTL on chromosome 12 (number 110 and 138) and 2 F2 plants heterozygous for only the 1-LOD region (number 132 and 185) were selfed. The F3 lines resulting from these selfings were used for QTL validation together with the references cv. Moneymaker and line R169.

All plants were grown in $17-\mathrm{cm}$ pots at Unifarm, Wageningen, The Netherlands at $21 / 19{ }^{\circ} \mathrm{C}$ (day/night temperature) at relative humidity of $70 \%$ with $16 / 8 \mathrm{~h}$ (day/night). Plants were randomized in the greenhouse.

\section{Whitefly resistance phenotyping}

Non-viruliferous $T$. vaporariorum was reared on tomato line RZ72-719 (Rijk Zwaan Breeding B.V.) under greenhouse conditions as described above. The resistance phenotyping using clip-on cages was carried out according to (Lucatti et al. 2013) on 6-weekold plants with 1-day-old synchronized female whiteflies. Phenotyping was done by attaching 3 clip-on cages containing 5 synchronized one-day-old female T. vaporariorum whiteflies on the abaxial side of the first, second and third fully expanded leaf of each plant. Five days later, living and dead whiteflies and the number of eggs present on the underside of the leaf were counted and used to calculate AS and OR, as described below.
Bemisia tabaci was also reared on tomato line RZ72-719 under the greenhouse conditions described above. Phenotyping experiments for AS and OR followed the same procedure as $T$. vaporariorum.

Thrips resistance phenotyping

The thrips Frankliniella occidentalis was reared on beans and the phenotyping for thrips resistance was done as described previously (Vosman et al. 2018). Plants were grown as described above. Five leaflets from the first or second fully expanded leaf were placed in a Falcon ${ }^{\circledR} 50 \mathrm{mmx} 9 \mathrm{~mm}$ Petri Dish with Tight-fit Lid in $1.5 \%$ water agar, with 5 Falcon dishes in total per plant. Five adult female thrips were placed in each Falcon dish. Petri dishes were incubated at $25{ }^{\circ} \mathrm{C}$ in a growth cabinet. Living and dead thrips were counted per leaf at 3 and 4 days after initial placement.

Data transformation

Whitefly AS and OR data, both B. tabaci and T. vaporariorum: Per plant the observations from the clip-on cages were combined, after removing cages with less than 3 remaining whiteflies (dead or alive) from the dataset. Data analysis was done according to Vosman et al. (2018). Oviposition rate was expressed as the number of eggs per average number of living females, calculated as $\mathrm{OR}=$ eggs/(living whiteflies + dead whiteflies/2). Adult survival was calculated as $\mathrm{AS}=$ living whiteflies/(living whiteflies + dead whiteflies). To normalize the data, AS data was transformed using $\operatorname{arcsine}(\operatorname{sqrt}(\mathrm{AS}))$ and the OR data was transformed as sqrt(OR). Frankliniella occidentalis survival was also calculated as (living/(living + dead)) and transformed as $\operatorname{arcsine}(\operatorname{sqrt}(\mathrm{AS}))$.

All statistical test were performed using IBM SPSS version 26 (IBM SPSS Statistics for Windows, Version 26.0 2019).

Validation of whitefly and thrips resistance in RIL lines

Three phenotyping tests were done to validate the QTL effect on resistance to T. vaporariorum resistance, in April, June and September 2016. In April and June, 5 randomized blocks with one plant of each of the 5 RILs per block were used. In the September 
experiment the plants were tested in three groups due to a limited supply of $T$. vaporariorum: Two plants each of RILs R020 and R040 were tested in one group, 5 plants each of RILs R015, R086 and R169 were tested together in a second group and 1 plant each of R020 and R040 were tested as a third group. Group 2 and 3 were tested 1 and 7 days after the first group. Plants were phenotyped for both adult survival (AS) and oviposition rate (OR) of $T$. vaporariorum. A 2-way anova with the factors line and experiment was performed with a Post-Hoc Fisher's least significant difference test.

In the B. tabaci experiment ten plants were used: 5 R169 and $5 \mathrm{cv}$. Moneymaker, which were placed in the same greenhouse compartment. Transformed data of B. tabaci AS and OR was compared between cv. Moneymaker and R169 using a Student t-test.

The thrips survival phenotyping was performed on 5 R169 and $5 \mathrm{cv}$. Moneymaker plants, grown in one compartment in the greenhouse. Transformed thrips survival data was compared between cv. Moneymaker and R169 using a Student t-test.

Genotyping and QTL analysis

RIL line R169, cv. Moneymaker and S. galapagense (PRI95004) were genotyped using the Solcap array (Sim et al. 2012). Markers that showed a polymorphism between R169 and cv. Moneymaker were identified and, from these, 106 markers (additional file 1) evenly spread over the 12 chromosomes were chosen for the genotyping of the F2 population. 181 F2 plants were phenotyped for both AS and OR, together with 10 R169 and $9 \mathrm{cv}$. Moneymaker plants, randomized over two greenhouse compartments. Genotyping was carried out by Rijk Zwaan Zaadteelt en Zaadhandel B.V., using the KASP assay (He et al. 2014). A genetic linkage map was constructed using the JoinMap 4.1 software (Van Ooijen 2006). Map distances were calculated using the Kosambi mapping function. Whitefly resistance QTLs were identified using MapQTL 6 (Van Ooijen 2009) with interval mapping and restricted MQM mapping using QTLs from the interval mapping as co-factors. A permutation test was performed with 1000 iterations on the whitefly parameters to determine the LOD-threshold with a significance level of 0.05 . The broad-sense heritability of the resistance trait was calculated using the F2 population and the R169 parental line that was phenotyped in the same experiment (Wray and Visscher 2008).

QTL validation

Per selected F3 line (lines 110, 132, 138 and 185) we aimed to phenotype 15 plants (5 homozygous for the cv. Moneymaker allele, 5 homozygous for the R169 (S. galapagense) allele and 5 heterozygous) for $T$. vaporariorum AS with $5 \mathrm{cv}$. Moneymaker and 5 R169 plants as reference. Plants of the F3 lines 132 and 185 were genotyped for the QTL region using the flanking markers solcap_snp_sl_59082 and solcap_snp_sl_42740, and plants of F3 lines 110 and 138 were genotyped using the flanking markers solcap_snp_sl_100122 and solcap_snp_sl_42740. For lines 132 and 185 only 3 plants homozygous for the MM allele were available, and for line 138 only 4 heterozygous plants were available. The validation experiment was analyzed using a 2-way anova with factors plant line and QTL genotype.

\section{Results}

Validation of $T$. vaporariorum resistance in RIL lines

The T. vaporariorum resistance phenotyping reported by Vosman et al. (2019) indicated that three RIL lines (R015, R086 and R169), on which trichomes type IV were absent, showed a reduced whitefly adult survival. This result was validated in 3 successive phenotyping experiments (Table 1). For both the AS and the OR there was a significant interaction between the experiment and plant lines ( $P=0.001$ for both AS and OR). Whitefly survival on the 3 RIL lines R015, R086 and R169 was significantly lower than on the susceptible R020 and cv. Moneymaker lines except for the R086 line in the June experiment. The trichome type IV carrying line R040 showed the lowest whitefly survival. Adult survival and OR of the highly susceptible (cv. Moneymaker and R020) and highly resistant (R040) accessions did not differ significantly between experiments, with the exception of OR in line R020. Differences between experiments for AS and OR were found in the intermediate lines R015, R086 and R169, with the highest AS and OR in June (except AS in R015). 
Table 1 Phenotyping data for the RIL lines and cv Moneymaker in three experiments

\begin{tabular}{|c|c|c|c|c|c|c|c|c|c|}
\hline \multirow[b]{2}{*}{ Accession } & \multicolumn{4}{|c|}{ Adult Survival } & \multicolumn{4}{|c|}{ Oviposition rate } & \multirow[b]{2}{*}{$W f 1$-Allele } \\
\hline & April & June & Sept & Mean & April & June & Sept & Mean & \\
\hline R015 & $0.37^{\mathrm{bY}}$ & $0.17^{\mathrm{abXY}}$ & $0.03^{\mathrm{ax}}$ & 0.19 & $2.4^{\mathrm{bXY}}$ & $5.9^{\mathrm{bY}}$ & $2.2^{\mathrm{bX}}$ & 3.5 & PRI91117 \\
\hline R020 & $0.92^{\mathrm{cX}}$ & $0.81^{\mathrm{eX}}$ & $0.92^{\mathrm{bX}}$ & 0.88 & $19.7^{\mathrm{eY}}$ & $14.8^{\mathrm{cXY}}$ & $11.6^{\mathrm{cX}}$ & 15.4 & PRI91117 \\
\hline R040 & $0.04^{\mathrm{aX}}$ & $0.03^{\mathrm{aX}}$ & $0.02^{\mathrm{aX}}$ & 0.03 & $0.8^{\mathrm{aX}}$ & $0.4^{\mathrm{aX}}$ & $0.1^{\mathrm{aX}}$ & 0.4 & PRI95004 \\
\hline R086 & $0.13^{\mathrm{abX}}$ & $0.47^{\mathrm{cdY}}$ & $0.07^{\mathrm{aX}}$ & 0.22 & $8.3^{\mathrm{cdY}}$ & $16.7^{\mathrm{cZ}}$ & $2.1^{\mathrm{bX}}$ & 9 & PRI91117 \\
\hline R169 & $0.00^{\mathrm{aX}}$ & $0.40^{\mathrm{bcY}}$ & $0.08^{\mathrm{aX}}$ & 0.16 & $4.0^{\mathrm{bcX}}$ & $15.8^{\mathrm{cY}}$ & $2.2^{\mathrm{bX}}$ & 7.3 & PRI91117 \\
\hline cv. Moneymaker & $0.79^{\mathrm{cX}}$ & $0.72^{\mathrm{deX}}$ & $\mathrm{Nd}$ & 0.76 & $8.3^{\mathrm{dX}}$ & $12.9^{\mathrm{cX}}$ & nd & 10.6 & PRI91117 \\
\hline
\end{tabular}

The $W f-1$ allele column displays from which accession the allele originates. PRI91117 is the cultivar Moneymaker and PRI95004 is $S$. galapagense as described by Firdaus et al. (2012)

Lowercase superscripts indicate LSD $(\mathrm{P}<0.05)$ grouping of the results per experiment, uppercase superscripts indicate LSD grouping within a line per month. Means are back-transformed to original scale. $N d$ : not determined

\section{Resistance of R169 to B. tabaci and F. occidentalis}

Phenotyping data for $B$. tabaci and F. occidentalis resistance is shown in Table 2. Adult survival of thrips F. occidentalis did not significantly differ between R169 and cv. Moneymaker for both day $3(P=0.43)$ and 4 day $(P=0.21)$. Survival of $B$. tabaci on R169 was significantly lower $(P=0.005)$ than on $\mathrm{cv}$. Moneymaker, but OR did not significantly differ between the 2 lines $(P=0.207)$.

QTL analysis and F2 comparison

The F2 population of a cross between cv. Moneymaker and R169 was phenotyped, together with the parents (Fig. 1). Oviposition rate did not differ between R169

Table 2 Phenotyping of RIL R169 and cv Moneymaker for Bemisia tabaci and Frankliniella occidentalis resistance

\begin{tabular}{lll}
\hline & R169 & Moneymaker \\
\hline Bemisia tabaci & & \\
AS & $0.86^{\mathrm{a}}$ & $0.9^{\mathrm{b}}$ \\
OR & $19.00^{\mathrm{a}}$ & $15.5^{\mathrm{a}}$ \\
Frankliniella occidentalis & & \\
AS day 3 & $0.47^{\mathrm{a}}$ & $0.4^{\mathrm{a}}$ \\
AS day 4 & $0.37^{\mathrm{a}}$ & $0.3^{\mathrm{a}}$ \\
\hline
\end{tabular}

AS: adult survival; OR: oviposition rate. Means are backtransformed to original scale

Superscript indicates significant differences $(\mathrm{P}<0.05)$ between the two accessions per parameter
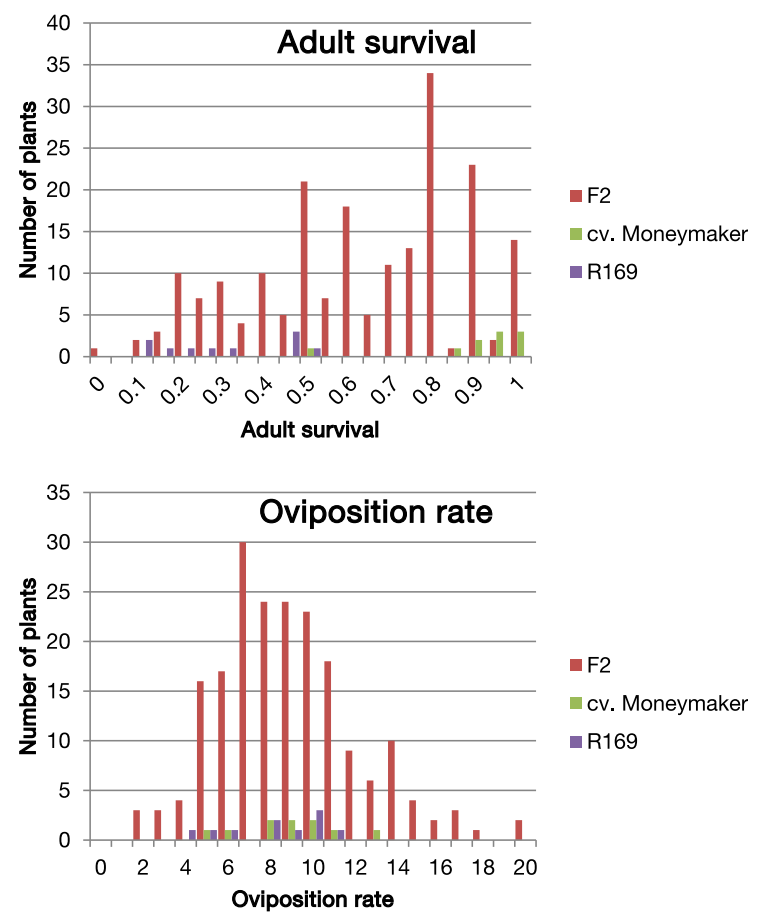

Fig. 1 Frequency distribution of adult survival (top) and oviposition (bottom) in the F2 population (181 plants), cv. Moneymaker and line R169

and cv. Moneymaker $(P=0.46)$, while AS showed a distinctly different distribution $(P=<0.001)$.

The phenotyping data was used in a QTL analysis. Interval mapping showed a QTL region on chromosome 12, with solcap_snp_sl_14428 as peak marker with a LOD of 5.4. The 2-LOD interval of the QTL, flanked by the markers solcap_snp_sl_42740 and 
solcap_snp_sl_100122, is approximately 381 kilobases, $36.7 \mathrm{cM}$ and explains $12.8 \%$ of the variation that was found for AS in the F2. We propose to call this QTL Ntr, non-trichome based resistance to T. vaporariorum. Using the peak marker of this QTL as cofactor in restricted MQM mapping, an putative additional minor QTL was found, with solcap_snp_sl_51748 as peak marker with a LOD of 3.04 and the 2-LOD interval flanked by markers solcap_snp_sl_45586 and solcap_snp_sl_53378 explaining $6 \%$ of the variance. Although the LOD of this additional QTL was less than the threshold value of 3.2 (determined by a permutation test with 1000 iterations), the use of the peak marker of each QTL increased the significance of the other QTL; for the main QTL on chromosome 12 the explained variation was increased to $13.9 \%$ and the peak LOD score to 6.2 (Fig. 2). The broad-sense heritability of the resistance trait $T$. vaporariorum AS was $63 \%$.

Ntr QTL validation

The F3 lines resulting from selfing of the selected F2 plants were phenotyped to validate the QTL (Table 3).
Table 3 Adult survival of Trialeurodes vaporariorum on 4 F3 lines per QTL-genotype

\begin{tabular}{llll}
\hline Accession & $\mathrm{H}$ & $\mathrm{MM}$ & $\mathrm{R} 169$ \\
\hline F3-line 185 & 0.69 & 0.78 & 0.57 \\
F3-line 132 & 0.69 & 0.96 & 0.66 \\
F3-line 138 & 0.53 & 0.76 & 0.56 \\
F3-line 110 & 0.67 & 0.88 & 0.65 \\
cv. Moneymaker & - & 0.88 & - \\
R169 & - & - & 0.60 \\
\hline
\end{tabular}

Columns MM and R169 indicate homozygosity for the Moneymaker and R169 (or S. galapagense) allele of the Ntr QTL, respectively, $\mathrm{H}$ indicates heterozygosity. Means are back-transformed to the original scale

The 1-LOD and 2-LOD region are flanked by the same marker on one side, solcap_snp_sl_42740, due to a limited number of segregating markers in that region. The 2-way ANOVA test indicated that the main effect of the factor plant line was insignificant $(P=0.319)$. Therefore a one-way ANOVA was used with the factor genotype of the Ntr-allele. Plants homozygous for the cv. Moneymaker Ntr-allele had significantly c07

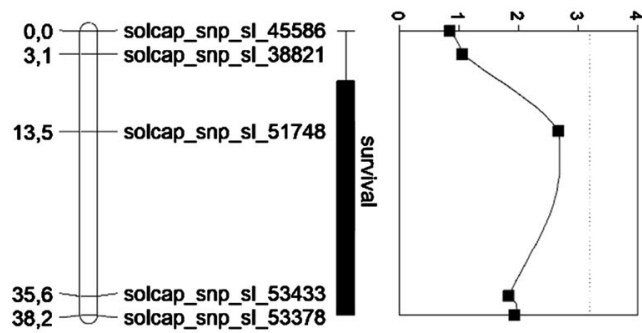

c12

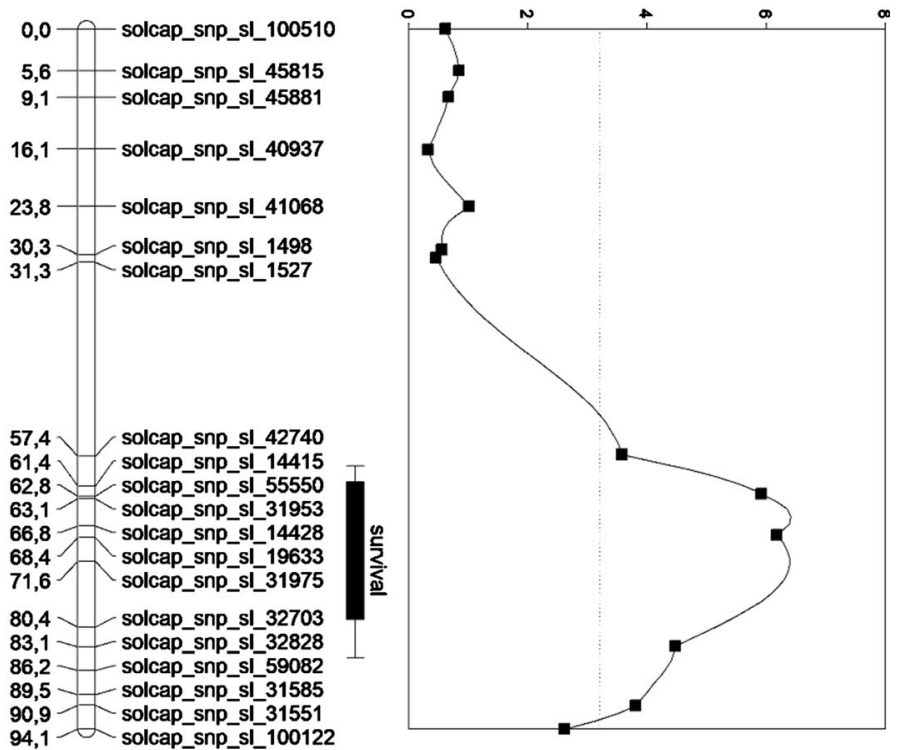

Fig. 2 QTL's found with restricted MQM mapping for Trialeurodes vaporariorum adult survival on chromosome 7 and 12. In both cases the left side shows the chromosome map with locus positions in $\mathrm{cM}$; the right side shows a graph of the LOD scores (dotted line represents the LOD threshold of 3.2, based on a permutation test with 1000 iterations). The 1-LOD and 2-LOD QTL support intervals are shown between the maps and the LOD graphs. Figures produced with MapChart (Voorrips 2002) 
higher AS than those homozygous for the R169 allele (which originates from $S$. galapagense) $(P=0.002)$ and heterozygous plants $(P=0.016)$. No significant difference was found between heterozygous plants and homozygous R169 Ntr-allele plants $(P=0.419)$.

\section{Discussion}

Whitefly resistance independent of trichomes type IV is present in $S$. galapagense and affects adult survival

The tomato wild relative $S$. galapagense PRI5004 is known to confer resistance to the whiteflies $B$. tabaci (Firdaus et al. 2012) and T. vaporariorum (Vosman et al. 2018). To a large extent this resistance can be explained by the presence of glandular trichomes type IV, for which a major QTL (Wf-l) was mapped on chromosome 2. In this study we show that another resistance mechanism, not based on trichome type IV, against $T$. vaporariorum is present as well in $S$. galapagense PRI5004. This novel non-trichome based resistance, which is amongst others present in recombinant inbred line R169, reduces $T$. vaporariorum adult survival (AS), but does not affect its oviposition rate (OR). We also show that B. tabaci AS is slightly, but significantly reduced on R169, compared to the susceptible cv. Moneymaker. R169 does not show enhanced resistance to the thrips $F$. occidentalis. The absence of effectivity to $F$. occidentalis and low impact on B. tabaci means that this resistance is rather specific. The trichome-based resistance in R040 is clearly more effective than the non-trichome-based resistance present in R169 against all three insects.

Only AS of $T$. vaporariorum, and not $\mathrm{OR}$, is affected by this resistance mechanism. Most previously identified non-trichome based resistance mechanisms against $T$. vaporariorum in tomato species affect either both OR and AS or OR alone (Maliepaard et al. 1995; McDaniel et al. 2016). This is also the case for B. tabaci resistance, with most QTLs for nontrichome resistance affecting both AS and OR (Lucatti et al. 2014; Momotaz et al. 2010). Recently, a QTL was found that only reduced AS for B. tabaci in $S$. pennellii on chromosome 11 (van den Oever-van den Elsen et al. 2016). A study on white cabbage ( $B$. oleracea capitata var. alba) with the whitefly Aleyrodes proletella showed a significant difference between susceptible and resistant plants for AS, but not for OR under greenhouse conditions. This resistance was suggested to be based on phloem compounds reducing sap ingestion by whiteflies (Broekgaarden et al. 2012). Identification of the underlying resistance genes is needed for further understanding of the resistance mechanism.

When compared with the metabolite QTL data collected by Vosman et al. (2019) on the whole RIL population, we find several metabolite QTLs that overlap with the Ntr QTL identified in the current study. One of these is a QTL for acyl sugar S3:13(4.4.5). Acyl sugars are linked to a reduced fitness of whiteflies (Firdaus et al. 2013; Vosman et al. 2018). However, the levels of S3:13(4.4.5) acyl sugars within the R169, R015 and R086 are relatively low. Additionally, 52 other metabolite QTLs identified by Vosman et al. (2018) were found to be (partly) overlapping with our Ntr QTL and could be involved in the resistance mechanism as well.

\section{Seasonal effect on the resistance}

In our resistance validation the factor experiment (April, June or September experiment) and the interaction between lines and experiments were significant factors for both AS and OR of T. vaporariorum. Lines R169 and R086 had significantly higher AS in the June experiment when compared to the April and September experiments, while line R015 had the highest AS in the April experiment. All the reference lines (cv. Moneymaker, R020 and R040) did not show a significant difference for AS and only reference line R020 showed a difference in OR per experiment, which suggests that seasonal variation was not due to variation in the whitefly populations used. However, it cannot be excluded that variation within the whitefly population could affect intermediately resistant lines more than highly susceptible or highly resistant lines. The OR was highest for all lines in June except for R020 and R040. R040 had low AS and OR throughout all 3 experiments, indicating as expected that trichomes type IV, when present, confer full resistance all year round.

It is known that seasonal variation, like differences in temperature or light conditions, can affect the resistance of plants to insect pests. Examples are resistance for the Phyllotreta nemorum larvae in Barbarea vulgaris, in which resistance decreases in 
the period from Augustus to November (Agerbirk et al. 2001). In the chrysanthemum Dendranthema grandiflora leaf damage by $F$. occidentalis was higher in winter for the partly resistant cultivar Lilac Byoux (de Kogel et al. 1997). Plant composition also changes throughout the season even under greenhouse conditions. Differences in the concentration of antioxidants like ascorbic acids, other constituents and dry matter percentage change throughout the year even in greenhouse grown tomatoes (Heuvelink 1995; Slimestad and Verheul 2005; Toor et al. 2006). The variation in the non-trichome based resistance could potentially be caused by such changes in metabolites and plant composition.

\section{A QTL on chromosome 12}

A QTL (Ntr) affecting non-trichome based resistance was mapped on chromosome 12 of tomato. The mean difference in AS between plants homozygous for the R169 or the Moneymaker allele across the F3-lines $132,138,110$ and 185 is $22 \%$. The 2-LOD QTL interval is located on chromosome 12 between 57.4 and $94.1 \mathrm{cM}$, a region with a length of 381 kilobases encompassing over 500 genes (Tomato genome SL 3.0). The explained variance for AS for the QTL is rather low with $13.9 \%$. Another putative minor QTL explaining $6 \%$ of the AS variance was identified on chromosome 7, between 0 and $38.2 \mathrm{cM}$. In our QTL validation (Table 3) AS in plants homozygous for the R169 allele did not differ significantly from that in line R169. The F3-line effect was not significant, in contrast to the Ntr genotype. The Ntr QTL explained $13.9 \%$ of the (phenotypic) variance in the F2; as the heritability was $63 \%$, the QTL was responsible for $22.1 \%$ of the genetic variance. The remaining genetic variance may be partially explained by the minor QTL on chromosome 7, but the major part must be due to non-detected genetic factors. This relatively small effect of a single QTL is in line with previous studies were similar observations were made for insect resistance (Broekgaarden et al. 2018; Perez-Sackett et al. 2011; van den Oever-van den Elsen et al. 2016). Since no significant difference was found between plants homozygous for the R169 allele and heterozygous plants, the resistance is a dominant trait and therefore not based on an S-gene mechanism (Pavan et al. 2009).
The control of $T$. vaporariorum in especially greenhouse environments can benefit from a resistance that is not based on glandular trichomes. Trichomes are known to have harmful effects on predatory biocontrol species, with studies indicating that glandular trichomes have the largest negative effect (Riddick and Simmons 2014). Parasitoid biocontrol species were also shown to have a lower rate of parasitism due to the presence of glandular trichome (Farrar and Kennedy 1991; Simmons and Gurr 2004; van Lenteren et al. 1995). In order to combine resistance factors with biocontrol, non-trichome resistance mechanisms are therefore preferred. New sources of resistance, like the Ntr QTL identified in this study and the non-trichome based thrips resistance identified by (Bac-Molenaar et al. 2019), can contribute to these combined pest control systems. Additionally, the combination of different resistance mechanisms provides a more durable resistance towards insect pests (Halpin 2005) and the introduction of this newly identified resistance could help in producing a durable resistance tomato cultivar.

Acknowledgements The authors would like to thank Rijk Zwaan Zaadteelt en Zaadhandel B.V. for carrying out the marker analysis for the QTL mapping experiment. This project was funded by a grant (TKI 1310-071) from the Ministry of Economic Affairs of The Netherlands and the breeding companies Axia Vegetable Seeds B.V., The Netherlands, Enza Zaden Research \& Development B.V., The Netherlands, Rijk Zwaan Zaadteelt en Zaadhandel B.V., The Netherlands and East-West Seed Company, Inc., The Philippines.

Author contributions BV and REV conceived and designed the experiments. $\mathrm{WvW}$ and $\mathrm{MB}$ carried out the whitefly experiments. JS, MB, REV and BV carried out data analysis and drafted the manuscript.

\section{Compliance with ethical standards}

Conflict of Interest The authors declare that they have no conflict of interest.

Open Access This article is licensed under a Creative Commons Attribution 4.0 International License, which permits use, sharing, adaptation, distribution and reproduction in any medium or format, as long as you give appropriate credit to the original author(s) and the source, provide a link to the Creative Commons licence, and indicate if changes were made. The images or other third party material in this article are included in the article's Creative Commons licence, unless indicated otherwise in a credit line to the material. If material is not included in the article's Creative Commons licence and your intended use is not permitted by statutory regulation or exceeds the permitted use, you will need to obtain permission directly 
from the copyright holder. To view a copy of this licence, visit http://creativecommons.org/licenses/by/4.0/.

\section{References}

Agerbirk N, Olsen CE, Nielsen JK (2001) Seasonal variation in leaf glucosinolates and insect resistance in two types of Barbarea vulgaris ssp. Arcuata Phytochemistry 58:91-100. https://doi.org/10.1016/S0031-9422(01)00151-0

Aktar W, Sengupta D, Chowdhury A (2009) Impact of pesticides use in agriculture: their benefits and hazards. Interdiscip toxicol 2:1. https://doi.org/10.2478/v10102-0090001-7

Allen WR, Broadbent AB (1986) Transmission of tomato spotted wilt virus in ontario greenhouses by frankliniella occidentalis. Can J Plant Path 8:33-38. https://doi.org/10. 1080/07060668609501838

Bac-Molenaar JA et al (2019) Trichome independent resistance against western flower thrips in tomato. Plant Cell Physiol 60:1011-1024. https://doi.org/10.1093/pcp/pcz018

Bi JL, Toscano NC (2007) Current status of the greenhouse whitefly, Trialeurodes vaporariorum, susceptibility to neonicotinoid and conventional insecticides on strawberries in southern California. Pest Manag Sci 63:747-752. https://doi.org/10.1002/ps.1405

Broekgaarden C, Snoeren TAL, Dicke M, Vosman B (2011) Exploiting natural variation to identify insect-resistance genes. Plant Biotechnol J 9:819-825. https://doi.org/10. 1111/j.1467-7652.2011.00635.x

Broekgaarden C, Riviere P, Steenhuis G, del Sol Cuenca M, Kos M, Vosman B (2012) Phloem-specific resistance in Brassica oleracea against the whitefly Aleyrodes proletella. Entomol Exp Appl 142:153-164. https://doi.org/10.1111/j. 1570-7458.2011.01210.x

Broekgaarden C et al (2018) Combining QTL mapping with transcriptome and metabolome profiling reveals a possible role for ABA signaling in resistance against the cabbage whitefly in cabbage. PLoS ONE 13:e0206103. https://doi. org/10.1371/journal.pone.0206103

Chomnunti P et al (2014) The sooty moulds fungal diversity: an international. J Mycol 66:1-36. https://doi.org/10.1007/ s13225-014-0278-5

de Kogel WJ, van der Hoek M, Dik MTA, Gebala B, van Dijken FR, Mollema C (1997) Seasonal variation in resistance of chrysanthemum cultivars to Frankliniella occidentalis (Thysanoptera: Thripidae). Euphytica 97:283-288. https:// doi.org/10.1023/A:1003080308129

De Ponti OMB, Pet G, Hogenboom NG (1975) Resistance to the glasshouse whitefly (Trialeurodes vaporariorumWestw.) in tomato (Lycopersicon esculentumMill.) and related species. Euphytica 24:645-649. https://doi.org/10.1007/ BF00132902

Dimock MB, Kennedy GG (1983) The role of glandular trichomes in the resistance of lycopersicon hirsutum $\mathrm{f}$ Glabratum to heliothis zea. Entomol Exp Appl 33:263-268. https://doi.org/10.1111/j.1570-7458.1983. tb03267.x
Duffus JE, Liu HY, Wisler GC (1996) Tomato infectious chlorosis virus-a new clostero-like virus transmitted by Trialeurodes vaporariorum. Euro J Plant Pathol Publ Cooperation Euro Found Plant Pathol 102:219-226. https://doi.org/10.1007/BF01877960

Erb WA, Lindquist RK, Flickinger NJ, Casey ML (1994) Resistance of Selected Interspecific Lycopersicon Hybrids to Greenhouse Whitefly (Homoptera: Aleurodidae). Florida Entomologist 77:104-116. https://doi.org/10.2307/ 3495877

Escobar-Bravo R, Ruijgrok J, Kim HK, Grosser K, Van Dam NM, Klinkhamer PGL, Leiss KA (2018) Light intensitymediated induction of trichome-associated allelochemicals increases resistance against thrips in tomato. Plant Cell Physiol 59:2462-2475. https://doi.org/10.1093/pcp/ pcy 166

FAO (2018) FAOSTAT statistical database. Food Agriculture Organization of the United Nations. http://www.fao.org/ faostat/en/\#home

Farrar RR, Kennedy G (1991) Inhibition of Telenomus sphingis an egg parasitoid of Manduca spp. by trichome/2-tridecanone-based host plant resistance in tomato. Entomol Exp Appl 60:157-166. https://doi.org/10.1111/j.1570-7458. 1991.tb01534.x

Fiallo-Olivé E, Navas-Castillo J (2019) Tomato chlorosis virus, an emergent plant virus still expanding its geographical and host ranges. Mol Plant Pathol 20:1307-1320. https://doi. org/10.1111/mpp.12847

Firdaus S, van Heusden AW, Hidayati N, Supena EDJ, Visser RGF, Vosman B (2012) Resistance to Bemisia tabaci in tomato wild relatives. Euphytica 187:31-45. https://doi. org/10.1007/s10681-012-0704-2

Firdaus S et al (2013) Identification and QTL mapping of whitefly resistance components in Solanum galapagense. Theor Appl Genet 126:1487-1501. https://doi.org/10. 1007/s00122-013-2067-z

Forget $G$ Balancing the need for pesticides with the risk to human health (1993). In: Impact of pesticide use on health in developing countries: proceedings of a symposium held in Ottawa, Canada, 17-20 Sept. 1990. IDRC, Ottawa, ON, CA

Gerling D, Alomar Ò, Arnò J (2001) Biological control of Bemisia tabaci using predators and parasitoids. Crop Prot 20:779-799. 2194(01)00111-9

Gorman K, Devine G, Bennison J, Coussons P, Punchard N, Denholm I (2007) Report of resistance to the neonicotinoid insecticide imidacloprid in Trialeurodes vaporariorum (Hemiptera: Aleyrodidae). Pest Manag Sci 63:555-558. https://doi.org/10.1002/ps.1364

Halpin C (2005) Gene stacking in transgenic plants-the challenge for $21 \mathrm{st}$ century plant biotechnology. Plant Biotechnol J 3:141-155. https://doi.org/10.1111/j.14677652.2004.00113.x

He C, Holme J, Anthony J (2014) SNP Genotyping: The KASP Assay. In: Fleury D, Whitford R (eds) Crop Breeding: Methods and Protocols. Springer, New York, pp 75-86. https://doi.org/10.1007/978-1-4939-0446-4_7

Heuvelink E (1995) Growth, development and yield of a tomato crop: periodic destructive measurements in a greenhouse. 
Sci Hortic 61:77-99. https://doi.org/10.1016/03044238(94)00729-Y

Horowitz R, Denholm I, Morin S (2007) Resistance to Insecticides in the TYLCV vector Bemisia Tabaci. In: Czosnek H (ed) Tomato yellow leaf curl virus disease: management, molecular biology, breeding for resistance. Springer, Netherlands, Dordrecht, pp 305-325. https://doi.org/10. 1007/978-1-4020-4769-5_18

IBM SPSS Statistics for Windows, Version 26.0 (2019). IBM Corp., Armonk, NY

Johnson MW, Caprio LC, Coughlin JA, Tabashnik BE, Rosenheim JA, Welter SC (1992) Effect of Trialeurodes vaporariorum Homoptera Aleyrodidae on yield of fresh market tomatoes. J Economic Entomol 85:2370-2376. https://doi.org/10.1093/jee/85.6.2370

Jones DR (2003) Plant viruses transmitted by whiteflies. Eur J Plant Pathol 109:195-219. https://doi.org/10.1023/A: 1022846630513

Kamikawa S, Imura T, Sato H (2018) Reduction of sooty mold damage through biocontrol of the greenhouse whitefly Trialeurodes vaporariorum (Hemiptera: Aleyrodidae) using selective insecticides in tomato cultivation greenhouses. Appl Entomol Zool 53:395-402. https://doi.org/ 10.1007/s13355-018-0570-Z

Knapp M, van Houten Y, Hoogerbrugge H, Bolckmans K (2013) Amblydromalus limonicus Acari: Phytoseiidae as a biocontrol agent: literature review and new findings. Acarologia 53:191-202. https://doi.org/10.1051/ acarologia/20132088

Lahey Z, Stansly P (2015) An updated list of parasitoid hymenoptera reared from the bemisia tabaci species complex (Hemiptera: Aleyrodidae). Florida Entomol 98(456-463):458

Lari SZ, Khan NA, Gandhi KN, Meshram TS, Thacker NP (2014) Comparison of pesticide residues in surface water and ground water of agriculture intensive areas. J Environ Health Sci Eng. https://doi.org/10.1186/2052-336X-12-11

Lucatti AF, van Heusden AW, de Vos RCH, Visser RGF, Vosman B (2013) Differences in insect resistance between tomato species endemic to the Galapagos Islands. BMC Evol Biol 13:175. https://doi.org/10.1186/1471-2148-13175

Lucatti AF, Meijer-Dekens FRG, Mumm R, Visser RGF, Vosman B, van Heusden S (2014) Normal adult survival but reduced Bemisia tabaci oviposition rate on tomato lines carrying an introgression from $\mathrm{S}$ habrochaites. BMC Genet 15:142. https://doi.org/10.1186/s12863-014-0142-3

Luckwill LC (1943) The genus Lycopersicon; an historical, biological, and taxonomic survey of the wild and cultivated tomatoes. Aberdeen University studies, The University Press, Aberdeen

Maliepaard C et al (1995) Mapping of QTLs for glandular trichome densities and Trialeurodes vaporariorum (greenhouse whitefly) resistance in an F2 from Lycopersicon esculentum $\times$ Lycopersicon hirsutum $\mathrm{f}$ glabratum. Heredity 75:425-433. https://doi.org/10.1038/hdy.1995. 155

Mansveld MHE-R, Lenteren JCV, Ellenbroek JM, Woets J (1982) The parasite-host relationship between Encarsia formosa (Hym., Aphelinidae) and Trialeurodes vaporariorum (Hom., Aleyrodidae). Zeitschrift für Angewandte
Entomologie 93:113-130. https://doi.org/10.1111/j.14390418.1982.tb03577.x

McDaniel T, Tosh CR, Gatehouse AMR, George D, Robson M, Brogan B (2016) Novel resistance mechanisms of a wild tomato against the glasshouse whitefly. Agron Sustain Dev 36:14. https://doi.org/10.1007/s13593-016-0351-4

Millar NS, Denholm I (2007) Nicotinic acetylcholine receptors: targets for commercially important insecticides. Invertebr Neurosci 7:53-66. https://doi.org/10.1007/s10158-0060040-0

Mirnezhad M, Romero-González RR, Leiss KA, Choi YH, Verpoorte R, Klinkhamer PGL (2010) Metabolomic analysis of host plant resistance to thrips in wild and cultivated tomatoes. Phytochem Anal 21:110-117. https://doi.org/10. 1002/pca. 1182

Momotaz A, Scott JW, Schuster DJ (2010) Identification of Quantitative Trait Loci Conferring Resistance to Bemisia tabaci in an F2 Population of Solanum lycopersicum $\times$ Solanum habrochaites Accession LA1777. J Am Soc Hortic Sci 135:134. https://doi.org/10.21273/jashs.135.2. 134

Muigai SG, Bassett MJ, Schuster DJ, Scott JW (2003) Greenhouse and field screening of wildLycopersicon germplasm for resistance to the whiteflyBemisia argentifolii. Phytoparasitica 31:27. https://doi.org/10.1007/BF02979764

Nauen R, Reckmann U, Thomzik J, Thielert W (2008) Biological profile of spirotetramat (Movento $\left.{ }^{\circledR}\right)$-a new twoway systemic (ambimobile) insecticide against sucking pest species. Bayer CropSci J 61:245-278

Nombela G, Williamson VM, Muñiz M (2003) The Root-Knot Nematode Resistance Gene Mi-1.2 of Tomato Is Responsible for Resistance Against the Whitefly Bemisia tabaci. Mole Plant-Microbe Interact 16:645-649

Oriani MADG, Vendramim JD, Vasconcelos CJ (2011) Nochoice ovipositional nonpreference of Bemisia tabaci (Gennadius) B biotype on tomato genotypes. Scientia Agricola 68:147-153

Pavan S, Jacobsen E, Visser RGF, Bai Y (2009) Loss of susceptibility as a novel breeding strategy for durable and broad-spectrum resistance. Mol Breeding 25:1. https://doi. org/10.1007/s11032-009-9323-6

Perez-Sackett PT, Cianzio SR, Kara PC, Aviles M, Palmer RG (2011) QTL Mapping of Whitefly Resistance in Soybean. Journal of Crop Improvement 25:134-150. https://doi.org/ $10.1080 / 15427528.2011 .546093$

Rakha M, Hanson P, Ramasamy S (2017) Identification of resistance to Bemisia tabaci Genn. in closely related wild relatives of cultivated tomato based on trichome type analysis and choice and no-choice assays. Genet Resour Crop Evolut 64:247-260. https://doi.org/10.1007/s10722015-0347-y

Riddick EW, Simmons AM (2014) Do plant trichomes cause more harm than good to predatory insects? Pest Manag Sci 70:1655-1665. https://doi.org/10.1002/ps.3772

Roberts P, Thomason J (1986) Variability in reproduction of isolates of Meloidogyne incognita and M. javanica on resistant tomato genotypes. Plant Dis 70:547

Schmidt RA (2014) Leaf structures affect predatory mites (Acari: Phytoseiidae) and biological control: a review. Exp Appl Acarol 62:1-17. https://doi.org/10.1007/s10493-0139730-6 
Selby TP et al (2013) Discovery of cyantraniliprole a potent and selective anthranilic diamide ryanodine receptor activator with cross-spectrum insecticidal activity. Bioorganic Med Chem Lett 23:6341-6345. https://doi.org/10.1016/j.bmcl. 2013.09.076

Sevik MA, Arli-Sokmen M (2012) Estimation of the effect of Tomato spotted wilt virus (TSWV) infection on some yield components of tomato. Phytoparasitica 40:87-93

Sim S-C et al (2012) High-Density SNP Genotyping of Tomato (Solanum lycopersicum L.) Reveals Patterns of Genetic Variation Due to Breeding. PLoS ONE 7:e45520. https:// doi.org/10.1371/journal.pone.0045520

Simmons AT, Gurr GM (2004) Trichome-based host plant resistance of Lycopersicon species and the biocontrol agent Mallada signata: are they compatible? Entomol Exp Appl 113:95-101. https://doi.org/10.1111/j.0013-8703.2004. 00210.x

Slimestad R, Verheul MJ (2005) Seasonal Variations in the Level of Plant Constituents in Greenhouse Production of Cherry Tomatoes. J Agric Food Chem 53:3114-3119. https://doi.org/10.1021/jf047864e

Soderlund DM, Bloomquist JR (1989) Neurotoxic actions of pyrethroid insecticides. Annu Rev Entomol 34:77-96. https://doi.org/10.1146/annurev.en.34.010189.000453

Toor RK, Savage GP, Lister CE (2006) Seasonal variations in the antioxidant composition of greenhouse grown tomatoes. J Food Compos Anal 19:1-10. https://doi.org/10. 1016/j.jfca.2004.11.008

van den Oever-van den Elsen F, Lucatti AF, van Heusden S, Broekgaarden C, Mumm R, Dicke M, Vosman B (2016) Quantitative resistance against Bemisia tabaci in Solanum pennellii: Genetics and metabolomics Journal of Integrative Plant Biology 58:397-412 doi:https://doi.org/10.1111/ jipb. 12449

van Lenteren JC, Hua LZ, Kamerman JW, Rumei X (1995) The parasite-host relationship between Encarsia formosa (Hym., Aphelinidae) and Trialeurodes vaporariorum (Hom., Aleyrodidae) XXVI Leaf hairs reduce the capacity of Encarsia to control greenhouse whitefly on cucumber.
J Appl Entomol 119:553-559. https://doi.org/10.1111/j. 1439-0418.1995.tb01335.x

Van Ooijen J (2006) JoinMap 4. Software for the calculation of genetic linkage maps in experimental populations. Kyazma BV, Wageningen

Van Ooijen J (2009) MapQTL 6, Software for the mapping of quantitative trait loci in experimental populations of diploid species. Kyazma B.V., Wageningen, The Netherlands

Vet LEM, van Lenteren JC, Woets J (1980) The parasite-host relationship between Encarsia formosa Hymenoptera: Aphelinidae and Trialeurodes vaporariorum Homoptera: Aleyrodidae. Zeitschrift für Angewandte Entomologie 90:26-51. https://doi.org/10.1111/j.1439-0418.1980. tb03499.x

Voorrips RE (2002) MapChart: software for the graphical presentation of linkage maps and QTLs. J Hered 93:77-78. https://doi.org/10.1093/jhered/93.1.77

Vosman B, van't Westende WPC, Henken B, van Eekelen HDLM, de Vos RCH, Voorrips RE (2018) Broad spectrum insect resistance and metabolites in close relatives of the cultivated tomato. Euphytica 214:46. https://doi.org/10. 1007/s10681-018-2124-4

Vosman B et al (2019) QTL mapping of insect resistance components of Solanum galapagense. Theor Appl Genetics 132:531-541. https://doi.org/10.1007/s00122-018-3239-7

Wisler GC, Li RH, Liu HY, Lowry DS, Duffus JE (1998) Tomato chlorosis virus: a new whitefly-transmitted, Phloem-limited, bipartite closterovirus of tomato. Phytopathology 88:402-409. https://doi.org/10.1094/PHYTO. 1998.88.5.402

Wray N, Visscher P (2008) Estimating trait heritability. Nature education 1:29

Publisher's Note Springer Nature remains neutral with regard to jurisdictional claims in published maps and institutional affiliations. 